\title{
'Routine Infrastructuring' as 'Building Everyday Resilience with Technology'
}

\author{
When Disruption Becomes Ordinary
}

BRYAN SEMAAN, Syracuse University, USA

Getting a divorce. Being diagnosed with a disease. Going through a relationship breakup. Living through a natural disaster. All of these events are often life disrupting and debilitating. While some disruptive events are short-lived, some can be a routine part of everyday life. This leads to the question of how people who experience prolonged disruption in their lives build resilience-that is, how do they manage and overcome such events? To explore this question, this paper utilizes a case study approach to explore the use, creation, and re-appropriation of technology across three prolonged disruptions-the Second Gulf War in Iraq, veteran transitions, and the coming out experiences of LGBTQ-identifying people. Using a conceptual frame that brings together routine dynamics and infrastructuring, we find that engaging in routine infrastructuring practices generated resilience in people's daily lives-a phenomenon we dub 'routine infrastructuring' as 'building everyday resilience with technology.' We then theorize properties of infrastructure and infrastructuring practice that enable resiliency, and conclude with how infrastructuring is a form of care work that is oriented towards individuals, communities, and society.

CCS Concepts: • Human-centered computing $\rightarrow$ HCI theory, concepts and models; Computer supported cooperative work; Empirical studies in collaborative and social computing.

Additional Key Words and Phrases: resilience, infrastructure, infrastructuring, routines, disruption, transition, crisis, identity, identity work, feminist design, care work, STS

\section{ACM Reference Format:}

Bryan Semaan. 2019. 'Routine Infrastructuring' as 'Building Everyday Resilience with Technology': When Disruption Becomes Ordinary. Proc. ACM Hum.-Comput. Interact. 3, CSCW, Article 73 (November 2019), 24 pages. https://doi.org/10.1145/3359175

\section{INTRODUCTION}

In their everyday lives, people experience a range of events that can be disrupting and debilitating. In some cases, disruptive events are highly visible in the public realm. Such visible events can be related to the external environment, as is the case with natural disasters like earthquakes and hurricanes, or human-induced, as is the case with war. In other cases, disruptive events can be invisible to the public and rest primarily within individuals and families. Such invisible events can take on many forms, such as being diagnosed with a disease, going through a relationship breakup, losing a job, going through a gender transition, and more. Importantly, when people experience prolonged disruptive events, disruption becomes a routine part of life that people must contend with every day.

Author's address: Bryan Semaan, Syracuse University, School of Information, 343 Hinds Hall, Syracuse, New York, USA.

Permission to make digital or hard copies of all or part of this work for personal or classroom use is granted without fee provided that copies are not made or distributed for profit or commercial advantage and that copies bear this notice and the full citation on the first page. Copyrights for components of this work owned by others than ACM must be honored Abstracting with credit is permitted. To copy otherwise, or republish, to post on servers or to redistribute to lists, requires prior specific permission and/or a fee. Request permissions from permissions@acm.org.

(C) 2019 Association for Computing Machinery.

2573-0142/2019/11-ART73 \$15.00

https://doi.org/10.1145/3359175

Proc. ACM Hum.-Comput. Interact., Vol. 3, No. CSCW, Article 73. Publication date: November 2019. 
Prolonged disruptive events are not new. What is new is that, today, people have access to an array of technological resources through which they can build resilience, where resilience is defined as the practices people develop to bounce back from, manage, and overcome disruption in their daily lives [44]. Here, we adopt a broad view of technology, which encompasses everything from Internet-enabled platforms like social media and online forums, hardware like laptops and flash drives, to other resources like electric generators.

In line with this emerging dialogue, $\mathrm{CHI}$ and $\mathrm{CSCW}$ have increasingly explored the relationship between technology and resilience [44,51,52]. The majority of these studies have examined the intersection between information and communication technology (ICTs), such as social media websites, and disaster recovery, e.g. for situational awareness [78]. These studies highlight the improvisational socio-technical behaviors people develop to build resilience in the short period following specific disaster events [80]. To a lesser extent, other studies have explored the uses of ICTs during life transitions [46], which often emerge in the aftermath of a life disruption, e.g. starting a new job. These studies have highlighted the role ICTs, such as social media and online communities, play in enabling people to seek support [46, 67, 68]. However, at present, we still lack systematic knowledge about how technological resources, writ broadly, enable resiliency in response to stressors that cause prolonged, routine disruption-that is, when people experience disruption everyday-and this research aims to address this gap.

To better understand how people undergoing prolonged disruptions to their routine lives use technology to build resilience, we draw on three cases of prolonged disruption: the Second Gulf War in Iraq, the transition experiences of United States (US) military veterans, and the "coming out" experiences of Lesbian, Gay, Bisexual, Transgender, and Queer (LGBTQ) people. Using a framework that brings together the concepts of routine dynamics from organizational science and infrastructuring from Science and Technology Studies (STS), we argue that the emergence of routine infrastructuring practices generated resilience in people's daily lives-a phenomenon we dub 'routine infrastructuring' as 'building everyday resilience with technology.' We then theorize properties of infrastructure and infrastructuring practice that enable resiliency, and conclude with how infrastructuring is a form of care work that is oriented towards individuals, communities, and society, more broadly.

\section{LITERATURE REVIEW}

\subsection{Routine Dynamics in Everyday Life}

People engage in a variety of routine practices as they go about their lives, such as attending work or school, socializing with friends or colleagues, watching television, preparing meals, and more. According to organizational scholars, routines are defined as recognizable patterns of action carried out by multiple actors in a context [18]. Traditionally conceived, routines have been conceptualized as stable and resistant to change [18], in part due to the way in which they are often associated with rules and norms, which promote inflexibility and make it difficult to manage unexpected events [18].

Empirical work, however, has shown that routines are adaptable, and can function outside of rules and norms [53]. This view, which has been dubbed routine dynamics, illustrates that people have agency in forming new routines and modifying existing routines. From this perspective, routines involve interdependent patterns of action, and are generative systems comprising two interacting parts: the ostensive and the performative [53].

The ostensive part consists of abstract patterns that participants use to guide, account for, and refer to specific performances of a routine, and may vary across people and over time. In other words, the ostensive part of a routine, the abstract pattern, is the larger overarching label for a 
given routine, such as booking travel or buying groceries. The performative part consists of specific performances by specific people, at specific times, in specific places. As such, the way in which people perform any given routine can be different, depending on the context. For example, when booking travel, people can perform this routine in a variety of ways. People may use a telephone to call a travel agent. Alternatively, people can travel to an agency and interact with a travel agent in person. Moreover, people may use Internet-enabled technologies, such as websites, to perform this pattern of action.

\subsection{Infrastructure Supporting the Enactment of Routines}

One entity that people often draw on to enact their routines is infrastructure. Traditionally conceived, infrastructure is the underlying foundation, or basic framework, of a large-scale system. ${ }^{1} \mathrm{~A}$ society relies on infrastructure to support routine functions. Systems, such as roads and freeways support people's ability to routinely travel to and from work. The power grid supports people's ability to routinely power their devices, like computers, in support of engaging in work practices, e.g. writing papers. The network infrastructure supports people's ability to routinely communicate with friends, family, and colleagues through e-mail and social media.

Whereas infrastructure is often construed as being physical (i.e. roads and freeways) and technical (i.e. wireless networks), information systems scholars have developed the concept of information infrastructure to show how ICTs are also infrastructure. Hanseth and Lyytinen [27], in their formative work, conceptualize information infrastructure as "a shared, evolving, heterogenous installed base of IT capabilities ... for delivering and using information services in a community." In this view, information infrastructures are comprised of information systems, such as databases, as well as Internet-enabled media, e.g. social media platforms like Facebook and Instagram [8, 27] Thus, information infrastructures, like physical infrastructure, also support our routines as they have become integral to people's ability to communicate, collaborate, and access and produce information across a range of contexts, such as within institutional settings, local communities, and in networking with people, more broadly.

Furthermore, Star and Ruhleder's [72] contribution to our understanding of the concept of infrastructure was to illustrate that infrastructure is, in fact, sociotechnical. They describe how physical and technical infrastructures are interwoven with human organizations and relationships-that is, the physical and technological components of infrastructure are actually animated by corresponding social practices. In building on this work, Lee, Dourish, and Mark [38] bring explicit attention to the importance of human infrastructure, and define it as "the arrangements of organizations and actors that must be brought into alignment in order for work to be accomplished." In this view, human infrastructure brings together people who are known (i.e., family and friends) and unknown (i.e., government-funded institutions) through both informal and formal ties, and people in a society depend on human infrastructure to support their routine engagements with the world, such as traveling to and from work and school, accomplishing work in organizations, and/or receiving healthcare. For example, the staff who implements and maintains the Electronic Health Record (EHR) systems that are used to store our medical data are essential to sustaining routine clinical practice, though the majority of people may only ever interact with primary care physicians and nurses. Thus, physical, technical, and information infrastructures are largely dependent on human infrastructure to function, and in turn, the human infrastructure is critical in supporting routine societal function.

\footnotetext{
${ }^{1}$ https://www.merriam-webster.com/dictionary/infrastructure
} 


\subsection{Infrastructure and Routine Practices in Disruption: A Resilience Perspective}

As described by Star and Ruhleder [72], infrastructure is often invisible-that is, it operates in the background, supporting our routine activities. In the event of a failure or change in infrastructureduring an infrastructural breakdown-the inner workings of the infrastructure become visible [72]. That is, people become highly cognizant of the presence of the infrastructure. For example, when highways and/or roads are under construction and we lose the ability to travel to work, we become aware of the presence of the physical infrastructure that supports this routine practice, as well as the members of the human infrastructure who emerge to try and resolve this breakdown, such as construction and maintenance crews. In the event of environmental disruptions, such as disruptions emerging from natural disasters and wars, the infrastructures people come to rely on to support their routine activities can be damaged and become visible, as people are no longer able to engage in the performance of routine activities.

In various types of life disruptions, the infrastructures that are in place to support people undergoing such disruptions often fail to address people's needs, and thus become visible. When people undergo these disruptions, they often generate routine performances centered around using infrastructure to address issues they are facing. For example, in the context of the transition experiences of United States military veterans, veterans often suffer from significant mental health issues, such as PTSD [36]. As such, veterans who are transitioning back into civilian society may come to rely on existing infrastructures, such as the Department of Veteran Affairs (VA), to receive routine support for their mental health issues. However, research indicates that the VA is not addressing the needs of veterans. Reports suggest that the VA is losing health records and is unable to address the needs of a growing veteran population [2].

Moreover, infrastructures can also become visible through how they themselves routinely disrupt people's lives. To further explore this phenomenon, we return to Star and Ruhleder [72] who describe how, because of their invisibility, infrastructures are shaping our routine engagements with our social world behind the scenes. Yet, the ways in which infrastructures shape our routines can have deleterious effects. On a broad level, for example, information infrastructures like Facebook have embedded invisible logics in the form of algorithmically curated news feeds that can influence our views and perspectives [39]. Similarly, in organizational contexts, the invisible logics embedded in work systems designed to guide work practices can be dislocated from how work actually happens [50]. These logics, in turn, have significant and often invisible power in shaping our perspectives and routines. This is especially important when considering that, as described by Bowker [7], invisible human actors often make the infrastructure work from behind the scenes. That is, infrastructures are designed, implemented, and maintained by people, and people are not value neutral. The values, perspectives, and biases that are built into infrastructures may be misaligned with the values, perspectives, and biases of those who use infrastructures, serving as routine sources of disruption.

The invisible logics that underlie infrastructure can especially create additional complexity for people undergoing life changes with marginalized identities. That is, people who are placed by society on the outside of what is considered normative based on various intersections of their identity, such as their race, gender, sexual orientation, and/or socioeconomic status [76], e.g. LGBTQ identifying individuals. People who identify as LGBTQ often experience life change through the "coming out" experience, during which they engage in routine, prolonged performances through which they make their inner self visible to themselves and society. This life change is best conceptualized as a form of identity work, which is a process through which people re-craft their sense of self [30]. Our identities define us as individuals; it is the self that we refer to and that others see us as. Importantly, the invisible routines and normative logics that perpetuate the infrastructures 
LGBTQ-identifying individuals inhabit everyday can discriminate against their identities [22, 34], thus making the infrastructure visible. For example, physical infrastructures, such as bathrooms, often enforce a gender binary of "male" or "female" for use, isolating people who might identity outside of that binary. Transgender individuals might feel uncomfortable inhabiting either space if they do not visibly fit into socially accepted articulations of either gender. Similarly, information infrastructures like facial recognition software can serve to further marginalize LGBTQ identity, as these systems serve as gender reduction mechanisms and may mis-identify people who have changed genders or who do not choose a gender [26]. As a result, LGBTQ people might struggle in their identity work when the infrastructures they inhabit routinely perpetuate heteronormative logics.

We wondered then, how people might utilize technology, once the infrastructure breaks down or they become aware of the biases inherent in existing infrastructures, to restructure their world and develop resilience. How might they use technology to manage and overcome prolonged disruption?

The concept of resilience finds its roots in both psychology and ecology [12, 43, 71], and the most common definition centers around the ability of a technical or human system to "bounce back" from threat or vulnerability [12]. In this view, scholars have explored resilience as a process and an outcome $[43,71]$. On the one hand, technical disciplines have explored resilience as a technical problem through which to understand how materials, like concrete, can withstand shock and bounce back, where the outcome is resilience [29]. For example, during a natural disaster, e.g. an earthquake, engineers who design structures want their structures to maintain their integrity and return to a normal state after experiencing shock. On the other hand, social scientists have explored resilience as a process through which human systems (i.e. individuals, groups, and organizations) improvise and adapt to changes in their environment, or psychological stressors, as a means of restoring normalcy $[43,71]$. For example, scholars have explored how individuals who suffer from psychological ailments, like post-traumatic stress disorder, manage and mitigate the effects of trauma.

Importantly, there does not exist an agreed upon definition of resilience and resilience is defined in myriad ways [71]. As described by Southwick and colleagues [71], definitions of resilience include: a stable trajectory of functioning after an adverse event; maintaining positive psychological wellbeing in the aftermath of adversity; the capacity of a system to adapt successfully to a disturbance; and as a process through which people draw on resources to sustain well-being. As such, these authors stress that scholars must continue to empirically operationalize resilience in situ, as the evocation of resilience can differ depending on the context.

In building on this discourse, to operationalize resilience for this paper, we focus on the improvisational, creative, and adaptive processes of resilience that characterize how people manage and overcome everyday disruption. Specifically, we deploy a resource-based perspective, whereby we define resilience as the creative and adaptive processes through which people draw on resources as a means of overcoming everyday disruption [81]. For example, prior work has found that when disruption occurs, people often improvise tools and/or equipment used to perform tasks [18]. Here, scholars have shown that in the aftermath of natural disasters, people often creatively repurpose resources to address emerging needs. For example, in the aftermath of natural disasters like hurricanes, people have creatively used doors as stretchers when resources are lacking. Moreover, as demonstrated by Feldman [18] when looking at the use of resources from an organizational perspective, as people's practices change, so do the ways in which they use resources. To this effect, the use of resources, such as materials and information, is contextual, their meaning and use changes depending on the situation. This is important for the study of disruption, because when people experience disruption, the meaning and use of resources can change accordingly. For example, whereas during "normal" situations people use Facebook to update family and friends on 
their daily lives, when experiencing disruption, people can use Facebook as a resource to obtain timely information as a means of mitigating emergent threats. Today, people have access to a range of technologies, such as social and mobile media, and they have agency in utilizing technological resources in developing sensible innovations on established routines as a means of developing resilience.

\subsection{Routine Infrastructuring as Resilience in Disruption}

Research in CSCW and CHI has a long history in this area. In this view, technology, and infrastructure more broadly, has been studied in relation to people overcoming crisis events, such as disaster and war-particularly how affected populations deal with, adapt to, and subsequently restore order in the aftermath through a recovery process $[24,41,51,56]$. Studies of crisis situation have found innovating behaviors associated with recovery processes in online settings [24, 41, 51, 56]. ICTs, such as blogs and online forums have enabled people from across the globe to participate in the crisis recovery process by providing assistance and aid, dissemination information, and providing social support $[24,41,51,56]$. Studies of the use of social media during disaster have looked at how people used Facebook and blogs to engage in distributed problem-solving activities [52], to provide emotional support and guidance [78], to receive up-to-date information from peer-to-peer networks [73], and to determine the safety of friends through status message updates [52].

Studies on the design of online transition spaces in health communities found that group norms around support and reciprocity are empowering [42], offering both a place for engagement and giving back [47]. Other studies have detailed how ICTs support transitions in the case of homelessness [37], residential moves [59, 60], the transition from high school to college [46, 47], relationship breakups [46, 47], domestic violence [13, 46], and job loss [9]. Other work in this area focuses on the use of ICTs, such as Facebook, blogs, and YouTube, during identity-based transitions, such as veteran transitions [65], coming out as LGBTQ [25], disadvantaged college students [48], and stay at home fathers [3]. These studies have found that while ICTs generally support people in obtaining support and resources in transition, that these technologies can also serve to further marginalize people undergoing transitions. For example, Haimson and colleagues [25], through an exploration of the use of Facebook by people undergoing gender transitions, found that the presence of family and friends can serve as a source of both support and stress. Similarly, Morioka and colleagues [48], in a study exploring the uses of Facebook by disadvantaged college students, found that social media platforms can make it difficult for people to identify supportive mentors with similar experiences. Moreover, Ammari and Schoenebeck [3], in a study of stay at home fathers, found that sharing experiences through Facebook about their experiences presents stigma Finally, Semaan and colleagues [65], in their study of veteran transitions, found that while veterans are utilizing social media platforms to understand the civilian world, that the presence of family and friends can create barriers to transition as the presence of family and friends can complicate their identity work.

Given that the infrastructures that people draw on during prolonged disruptive life events can be damaged and/or serve as further sources of disruption and marginalization, we believe people can work around these issues is by relying on alternative infrastructures, repurposing existing infrastructures, or building new infrastructures, as a means for developing resilience. This leads to the question proposed by Star and Ruhleder [72]: "When is infrastructure?" The answer to this question is seen in the practice of infrastructuring-which is the intentional production of infrastructure as a means of achieving a particular goal or the desire to solve a particular problem (i.e., bridging an infrastructural gap) [17, 77]. In this view, infrastructure is often defined in use-that is, how an infrastructure is defined depends largely on the individuals and communities that design, maintain, and use it. The interaction between users and infrastructures changes with the situation, 
shaping infrastructure continually. Thus, infrastructure is not simply a substrate to be used or acted upon; rather, infrastructure is an ongoing alignment between people and contexts.

Against this backdrop, we explore the ways in which people who experience everyday disruption routinely use, re-appropriate, and build purposeful infrastructure to develop resilience. Sometimes, infrastructuring is a means to upend existing infrastructures-what Egyedi [16] refers to as creating inverse infrastructures. This type of infrastructuring can reveal power differentials in society; other times it can allow for the provision of self-organized or decentralized control among stakeholders In other words, inverse infrastructures-and their related practices of infrastructuring-provide a means to counter large-scale, formalized infrastructures, which are typically centrally controlled even if widely distributed. Infrastructuring has been also noted as a means to promote civic engagement and civic hacking [35]; support repair work [31]; enable mobile work [17]; and influence ICT design [54].

Moreover, scholarship has also explored the uses and design of technology amongst marginalized populations, such as immigrants and refugees $[1,63,79,83]$. Here, researchers have developed computer clubs in various socio-cultural contexts and developed collaborative projects in an effort to aid displaced populations [1, 63, 79, 83]. In their formative work, Weibert and Wulf [79] studied the development and use of emergent computer clubs in Germany. They found that through collaborative projects developed in these clubs, migrants were strengthening their social bonds in their new multicultural neighborhoods, while simultaneously developing skills (i.e. learning about computers) that enabled them to find employment as well as maintain ties with their home environments. Similarly, Schubert, Weibert, and Wulf [63] through a detailed exploration of two computer club projects in Germany, find that collaborative projects (i.e. a mesh network) enable integration as refugees were adapting the projects to reflect their needs and social structures, making the systems useful for others undergoing similar processes. Finally, Aal et al. [1], in adapting the computer club approach experiences in Germany to refugee camps in Palestine, found that the use of ICTs within these clubs enabled participants to become more civically engaged members of their own societies. Taken together, these studies highlight the intentional production of spaces designed to promote integration through collaboration amongst multiple stakeholders (i.e. researchers, designers, community members).

In this paper, we build on prior work through an exploration of self-organized infrastructures amongst populations affected by everyday disruption. We argue that the routine practice of infrastructuring enables people to build resilience when experiencing prolonged disruptions across contexts, highlighting different forms of infrastructuring as dependent on the situation and disruptive event. That is, we explore the social and cultural practices associated within the creation and re-appropriation of infrastructures amongst populations experiencing prolonged disruption in their everyday lives.

\section{ROUTINE INFRASTRUCTURING AS BUILDING EVERYDAY RESILIENCE WITH TECHNOLOGY}

In building on previous work, we turn to consider three cases of prolonged disruption. The first reports on a human-induced disruption in the form of war, and explores the ways in which Iraqi civilians engaged in routine infrastructuring during the Second Gulf War to maintain the practices of everyday life. The second reports on the bottom-up, routine development and maintenance of infrastructure by United States military veterans, as a means of creating alternative systems to support veterans who were experiencing long-term transitions back into civilian society, where the existing formal infrastructures were not serving them. The third case explores the re-appropriation of existing infrastructure amongst LGBTQ people undergoing the "coming out" experience-an experience that starts at birth and can last a lifetime-as a means of creating safe spaces through 
which they could enact an LGBTQ identity, whereas the infrastructures they inhabit routinely perpetuate heteronormative logics that make this experience difficult. Each disruption is substantial and prolonged, highlighting challenges associated with connecting to and making use of infrastructure (informational, social, digital, physical). Each case study is the result of substantial qualitative fieldwork conducted in these settings.

\subsection{Infrastructuring During the Second Gulf War in Iraq}

War environments provide a unique opportunity through which to explore infrastructuring practices, as the infrastructures people come to rely on to engage in routine activities can be severely damaged or destroyed altogether. To better explore the ways in which people develop routine infrastructuring practices as a means of building resilience in their everyday lives, this case draws on a qualitative interview study (conducted between September 2007 and May 2011) with 90 Iraqi civilians who were living in Iraq during the Second Gulf War which began in March 2003 [44, 45, 64]. Interviews were semi-structured life histories that explored people's lives before and after the war, and focused on uncovering the role technological resources play in repairing people's daily practices when living in disrupted environments.

Our informants were diverse in gender ( 40 female, 50 male), age (ranging from 18 to 60 years old), education (the majority of participants had a Bachelor's degree or were enrolled in postgraduate education), and profession (professors, journalists, translators, doctors, and taxi drivers). Participants hailed from large urban cities in southern Iraq (i.e. Babel and Basra), central Iraq (i.e. Baghdad), and northern Iraq (Mosul and Arbil).

Prior to the start of the Second Gulf War, Iraq's citizens had experienced and lived through successive disruptions: the Iraq-Iran war beginning in 1980 and ending in 1988, the First Gulf War beginning in 1990 and ending in 1991, the United Nations (UN) imposed embargo (beginning in 1991) and lasting almost 13 years, along with numerous attacks from the United States throughout the years of the embargo, all of which combined to weaken existing infrastructures and limit people's ability to engage in the routine practices of life.

Whereas the Iraq-Iran war, the First Gulf War, and the UN embargo successively weakened existing infrastructures, according to the United Nations High Commissioner for Refugees (UNHCR), the Second Gulf War was the most destructive. ${ }^{2}$ Prior to 2003 and the start of the Second Gulf War, for example, informants described how the communication infrastructure (i.e. landlines), electric infrastructure, travel infrastructure, education infrastructure, and water sanitation systems all functioned reasonably well, or well enough such that people could engage in routine performances, e.g. traveling to work and school, or powering the devices, such as refrigerators and stoves, that allowed them to prepare food. The Second Gulf war, however, disrupted many of these infrastructures (as we will elaborate in subsequent sections), which made engaging in routine performances a burden. For example, bombings made it difficult for people to travel safely and securely.

Before the Second Gulf War Iraqis had very limited access to technology, especially Internetenabled technology like social media, and ICTs, such as mobile phones (save for a governmentdeveloped and monitored Intranet deployed by the Ba'athist regime in 2001). When the Second Gulf War started and Saddam's regime was toppled, sanctions were lifted and several technologies entered the country. Through interviews, we learned that informants adopted a variety of technologies, ranging from mobile phones and Skype, to flash drives and electric generators. Based on our analysis, we learned that informants drew upon technological resources to engage in routine infrastructuring performances to address everyday issues in the war environment. By conducting an ongoing study over almost a four-year period, we were able to capture and document long-term,

${ }^{2}$ https://www.unhcr.org/4709f79a2.pdf 
evolving infrastructuring practices by Iraqi civilians from when the war began in 2003 until our interviews ended in 2011 (a period of seven years). Here, we will describe two of these engagements, which include: filling gaps in infrastructure by building redundancy, and repairing infrastructure.

\subsubsection{Filling Gaps in Infrastructure by Building Redundancy: The Case of the Electric Infrastructure.} In our daily lives, and especially in Western contexts, one type of physical infrastructure we often take for granted is the electric infrastructure. In the context of people's everyday lives, electricity is central to how we perform in many of the routine activities that make up our daily lives, such as communicating with others through email or via social media. Whereas before the Second Gulf War our informants described how the government maintained a mostly stable and reliable electric infrastructure, the situation became dire during the war.

Starting in 2003, between attacks on the infrastructure by US forces, and militia attacks on power stations and other government operated sources of energy, our informants described how they only had electricity on average one to four hours per day. This made engaging in the routine performances of daily life a burden, as people could not readily power devices in their homes and workplaces. For example, people could not reliably engage in the performance of cooking, as they were never sure when they would have electricity to power their stoves. Similarly, people could not depend on the existing electrical infrastructure to power their refrigerators and keep food fresh. Moreover, people could not easily power Internet-enabled technologies, such as computers and routers, making it difficult to routinely communicate with friends and family. Knowing that power outages were a normal occurrence, informants began to engage in routine infrastructuring performances such that they were creating redundant sources of electricity through the adoption and use of electric generators. By actively building redundant sources of electricity, informants were filling gaps in the electric infrastructure.

All of our informants reported how Iraqis began to adopt electric generators in the aftermath of the war. However, in order to power the generators, fuel was required and, given the abundance of oil in the country, was paradoxically difficult to obtain. Informants described how fuel to power generators was in short supply because oil refineries were targeted by militia groups that entered the country when the war commenced. As such, people were forced to wait in long lines to purchase fuel, while also risking their own lives through exposure to potential bombings and militia attacks in public spaces. As described by one informant:

"Well... before the war we used to buy fuel... car fuel was everywhere and available at any time. The gas, the electricity was available. Before the war electricity was only shut down 2 hours a day. After the war there was a huge decline. [Fuel] was hard to get. There was a queue in the gas station, sometimes it may take 8 hours, 10 hours to get gasoline. And you may not reach your turn, you may be waiting for 6 hours, 8 hours and there is no more fuel. The electricity now is only here for 1 to 4 hours a day. Sometimes you would face 3 days or a week without electricity. We had to use generators instead, but the funny thing is that we needed gas to use the generators! [Laughter]"

Despite these conditions, our informants described developing new infrastructuring performances whereby they would travel to obtain gasoline to power their generators, every day. Initially, all of our informants described how people began purchasing and installing electric generators in their own homes, and putting their lives at risk to obtain the gasoline to power their generators. Over time, however, many Iraqis started to install large community generators in their neighborhoods, and through makeshift wires, were able to deliver electricity to others for a flat fee. Here, while this performance initially started out as a means of building the capacity to maintain the routines of everyday life for themselves and their families, such as cooking and powering devices, it gradually 
shifted to where people were turning towards entrepreneurial endeavors to also sustain their livelihood.

3.1.2 Repairing Infrastructure: The Case of Education. In our daily lives, one type of infrastructure we often take for granted is the infrastructure that supports our ability to obtain an education Similarly, our informants described how, before the Second Gulf War, higher education in Iraq was of an international standard, which is corroborated by reports. ${ }^{3}$ Despite prior conflicts and the UN embargo, the basic infrastructure supporting education remained intact. ${ }^{4}$ That is, the educational system was staffed by qualified personnel, such as trained educators with $\mathrm{PhDs}$ and medical degrees, the materials needed to maintain educational routines, such as microscopes and copy machines, were readily available, and, importantly, it was easy to travel to and from the university to attend lectures, take notes, and participate in labs.

During the war, however, people's ability to reliably perform their routines as students, was severely disrupted. This was due to disruptions in the infrastructure supporting education. First, there was a large outflux of qualified personnel who were previously in place to educate the next generation of students because educators with $\mathrm{PhDs}$ and medical degrees were often targeted by militia and insurgent groups-that is, they were routinely being kidnapped, and even murdered, causing many educators to emigrate from Iraq. Second, soon after the war started, universities were the target of looting, and the equipment that was critical to performing educational routines, such as microscopes and other equipment, were no longer available. Finally, as a result of stochastic threats like bombings, the ability to safely and reliably travel to and from any given university became difficult.

In our study, we interviewed thirty medical students at various universities in Iraq. One element of resilience deals with the way in which people assume multiple roles, or develop new roles [80]. We found that, in an effort to restore order, our informants indeed began to assume new roles, through which they were routinely engaging in infrastructuring in an effort to repair the infrastructure that supports education. That is, students took it upon themselves to collectively engage in new routines through which they were creating a robust educational infrastructure where they and other students could maintain educational routines even when they could not attend lectures or labs, thus their practices were centered around the collective good.

Medical school in Iraq is typically a five-year process. When people first begin medical school, they are part of a cohort-a group of peers who are at the same stage-who go through the entire process together. That is, all students in any respective cohort are typically enrolled in the same courses and must also participate in the same labs. Being highly cognizant of the fact that not everyone could readily attend lectures, students in each cohort elected a group of students, typically three or four, who would ensure that people who could not routinely attend lectures and labs could remain up-to-date.

Initially, in an effort to achieve this goal, the elected students assumed new roles as note takers, where they would routinely attend lectures and either write or type notes. As a means of ensuring that all students could have access to materials, students adopted and used an array of technological resources in service of this goal. For example, they would use copy machines and make copies of their written notes, which they then made available to students by placing them in a central office on campus where, when a student was finally able to come to class, they could obtain the materials they had missed. Similarly, students also started using CDs and flash drives to achieve the same result, where they would make materials available digitally for others.

\footnotetext{
${ }^{3}$ https://wenr.wes.org/2017/10/education-in-iraq

${ }^{4}$ https://wenr.wes.org/2017/10/education-in-iraq
} 
Over time, however, as medical students began to repurpose digital infrastructures as a means of creating make-shift educational environments akin to Blackboard. Here, our medical student informants created private Facebook groups for each cohort, where students could obtain relevant information and materials as a means of maintaining their routines as students. Students used these private groups to share information about courses, such as exam dates and lecture notes, as well as practice exams (see Figure 1).

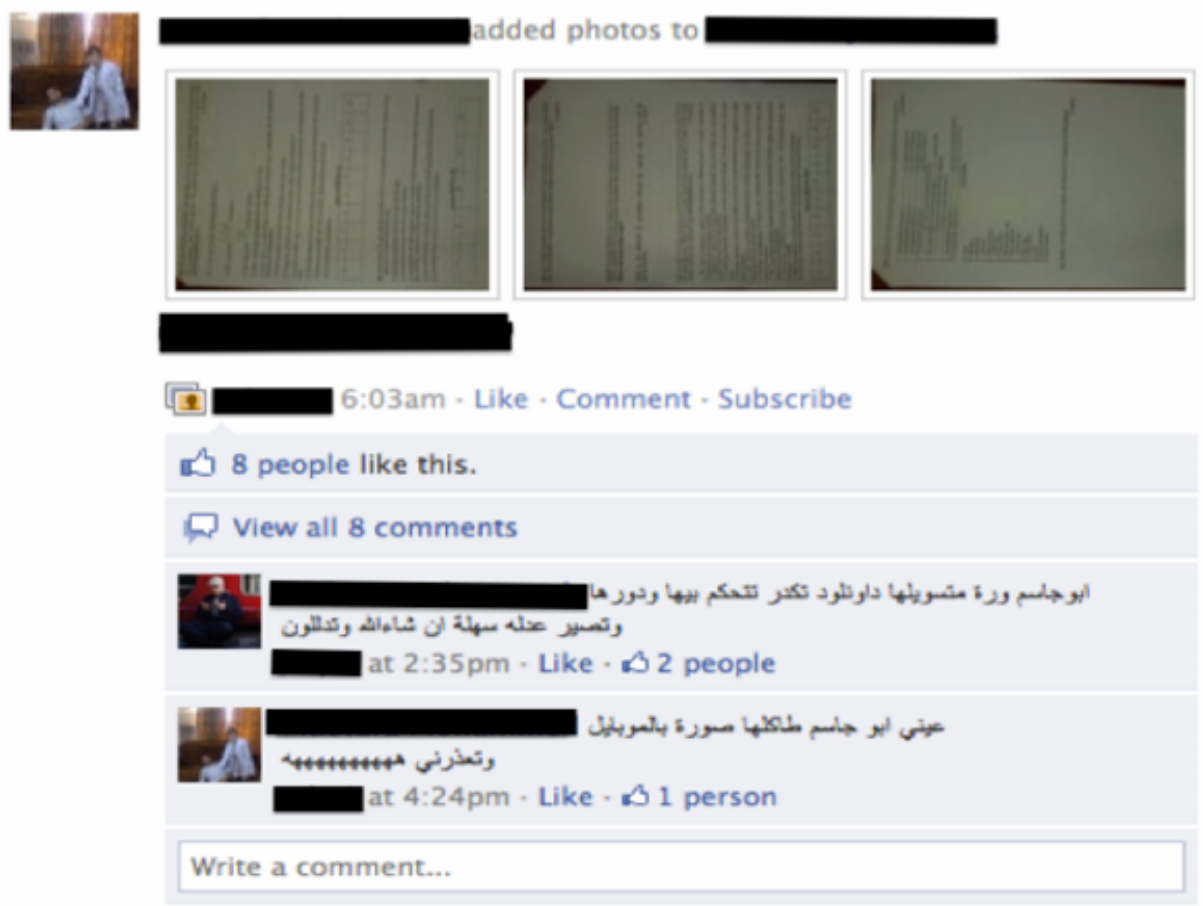

Fig. 1. Sharing a practice exam via Facebook.

Moreover, after faculty released grades of assignments and exams, they often posted these materials on their doors. Knowing that their peers could not routinely travel to the university, the students who were elected to maintain and curate information for their respective courses would use digital cameras to take photos of the grades, and use the tagging feature of Facebook to make their peers aware of their availability so that they could check their grades once they were available.

As such, medical students, through routine infrastructuring performances, and the enactment of new roles, were building resilience in the infrastructure that supports education.

\subsection{Infrastructuring in Veteran Transitions}

This case is based on a qualitative interview study (conducted between November 2014 and February $2019)$ with 70 veterans as they transition from military service back into civil society $[65,66]$. The focus of this study was centered on understanding the emergent transitional challenges faced by veterans, and how they utilize technological resources to manage and overcome everyday transition challenges. Interviews were semi-structured life histories where we asked people about their lives before, during, and after armed service. When investigating the transition phase, we asked people 
to describe their lives from when they first returned until the present, their daily routines, and issues they faced and how they worked around these issues. When informants discussed use of various technologies, we asked them more about how and why they used them.

Our informants were diverse in gender (50 men and 20 women), age (ages ranged from 2956 years of age), educational backgrounds (no college to $\mathrm{PhDs}$ ), and profession (for example, unemployed, project managers, students, entrepreneurs, nurses, and corporate technology support). We interviewed Army, Navy, Air Force, and Marines veterans who held a range of positions while serving, such as infantry, officers, and technical infrastructure engineers. Fifty of our participants enlisted in the military as adolescents from low-income environments, whereas 20 were enrolled in college Reserve Officer Training Corps (ROTC) programs and entered the military with positions of leadership.

Importantly, the veteran transition process is a prolonged endeavor-it can last several years and even decades [62]. This is due to the complexities of the veteran transition process-that is, veterans experience several transitions at once. After returning home, veterans can suffer from post-traumatic stress disorder (PTSD) and/or military sexual trauma (MST) [75] which can lead to other issues, such as homelessness [49]. These issues are related to what Collins [11] refers to as the civil-military cultural gap-that is, the routines and normative logics of the military are in stark contrast to the routines and normative logics of civilian society, and veterans often experience difficulty in acclimating to the routines and normative logics comprising civilian society.

When people join the military, they are deconstructed from their civilian self and reconstructed into a member of the military. Whereas being a member of the military is often misconstrued as an occupation, the military is best characterized as a total institution [70], which are closed systems organized by strict logics, rules, and norms that are carried out by a single authority. In total institutions, people must follow normative rules and logics when organizing their daily routine under restrictions imposed by the institution as authoritarian system. While the routines and normative logics of the civilian world tend to be centered on individualism and liberty-based values, military routines and logics are anchored on the values of collectivism and camaraderie [62, 65] that honor the group over the individual, and stress obedience to group-identified authorities, group-tested routines, and merit-based rewards. For example, while in the military, every aspect of one's life is structured and accounted for, like when to go to the doctor or to eat, which is not true of civilian society. Thus, the military is a cultural institution, and in this view, the culture of the military is as well-defined as other cultures, such as Chinese or Indian culture, where people, as members of the culture, understand and practice the routines and normative logics that define that culture.

Today, the primary government-developed infrastructure in place to assist veterans in their transitions is the Department of Veteran Affairs (VA). The VA, which is clinical in orientation, was developed to provide veterans with a range of in-person and online health services, ranging from psychological counseling to rehabilitation from service-related physical injuries like traumatic brain injury (TBI) and amputation [57]. However, the VA is failing to address the needs of the ever-expanding veteran population $[62,65]$. Reports indicate that the VA often loses health records $[62,65]$, that it can take months and sometimes years to gain access $[62,65]$, and veterans are generally unhappy with the services they are provided, or the lack thereof [62, 65].

Interviews revealed that the veteran transition experience is long-term-that is, although our informants were discharged from active duty anywhere between 3 months to 20 years at the time of our study, they were still struggling with myriad transitional issues. Whereas formal infrastructures, e.g. through the VA, were failing the veteran population, we learned that our informants had adopted, used, re-appropriated, and developed veteran-specific digital and hybrid offline and online infrastructures through social media platforms like Facebook and online forums like Reddit. 
Table 1. Summary of Veteran Developed Infrastructures

\begin{tabular}{l|l} 
Infrastructure Pseudonym & Description \\
\hline \hline PTSD Support and Recovery & $\begin{array}{l}\text { A closed Facebook group that was designed to assist } \\
\text { veterans in managing PTSD. This infrastructure brings } \\
\text { together veterans who are trained as counselors with } \\
\text { veterans who are suffering from PTSD. The goal is to } \\
\text { connect vulnerable veterans with others who can help } \\
\text { them through issues that may cause a trigger and lead to } \\
\text { suicide. It currently has 3,354 members. }\end{array}$ \\
\hline Sexual Assault Awareness & $\begin{array}{l}\text { A closed Facebook group designed to serve as a space for } \\
\text { marginalized veterans to develop community, as well as } \\
\text { to advocate for the collective needs of service men and } \\
\text { women who experienced issues such as Military Sexual } \\
\text { Trauma (MST). It currently has 13,647 members. }\end{array}$ \\
\hline Job Seeking and Integration & $\begin{array}{l}\text { A hybrid transition infrastructure, e.g. in person groups, } \\
\text { GroupMe chat groups and a Facebook group, which was } \\
\text { into the Workforce }\end{array}$ \\
& $\begin{array}{l}\text { mating to the civilian workforce. Its organizer describes } \\
\text { his vision as promoting veteran independence through } \\
\text { small business ventures and connecting veterans to one } \\
\text { another. It currently has 1,300 members. }\end{array}$ \\
\hline Suicide Mediation & $\begin{array}{l}\text { A closed Facebook group that promotes awareness of } \\
\text { veteran suicide and provides community support to ser- } \\
\text { vice members to help prevent suicide and help mitigate } \\
\text { suicidal ideation. It currently has 8,626 members. }\end{array}$ \\
\hline
\end{tabular}

Importantly, our analysis uncovered that informants were drawing on technological resources to engage in routine infrastructuring performances to address everyday issues in transition. Even for our participants who had been transitioning for 10 years, they described how adapting to civilian society is an ongoing, prolonged process, enabling us to capture and document longterm infrastructuring practices amongst the veteran population. Veteran transitions provide a unique context through which to explore emerging routine infrastructuring practices, as the formal infrastructures available to them are inadequate. Here we will describe two of these engagements, which include: building bottom-up infrastructures, and infrastructuring as rebuilding the self.

3.2.1 Building Bottom-Up Infrastructures: Re-Purposing Military Culture for the Civilian World. Through our analysis of informant accounts, we find that existing services through formal infrastructures, such as the VA, were not serving the needs of the veteran population. This is best illustrated by the following exemplary quote:

"There's a social element and a physical element to reintegrating that's missing with existing services. The VA, for instance, is geared towards those who were injured-they tend to focus purely on physical injury. While they aim to also deal with mental health issues, those services are highly inadequate."

All of our informants, however, described adopting or re-purposing their use of digital infrastructures, such as through social and mobile media, to mediate their transition experiences. More specific to infrastructuring, we found that veterans are developing bottom-up digital and hybrid 
offline and online infrastructures in service of other veterans. Here, a small subset of veterans-all of which held leadership positions in the military-were re-appropriating social media platforms, primarily by developing veteran-specific Facebook groups and GroupMe communities. That is, informants had taken it upon themselves to build and routinely maintain infrastructures to address the evolving needs of the veteran community. These services, many of which are health and wellness focused, vary in form and function, and include but are not limited to (1) PTSD support and recovery, (2) sexual assault awareness, (3) job seeking and integration into the workforce, and (4) suicide mediation. Table 1 describes the overall design intention behind these infrastructures, while highlighting the technological resources used to develop them.

Importantly, when designing these spaces, informants described how they purposefully designed them to be familiar to veterans-that is, they designed affordances that adhered to the routines and normative logics of military culture. To illustrate this, we return to one of the primary values of military culture-camaraderie-which is exemplified by "having each other's backs." That is, when deployed, military members develop a strong "brotherhood" and "sisterhood" with one another, and this is performed through a responsibility model [61], whereby people assume responsibility for those around them. For example, when military personnel engage in combat, everyone in a unit assumes responsibility for one another's lives. We found that the designers of these spaces, who were veterans also undergoing transitions or who had found success in their transitions, designed them such that veterans could continue to perform the routines of military life, but in civilian contexts. For example, the online community developed for suicide mediation includes the exchange of phone numbers such that if a member is having suicidal thoughts, they can reach out to other veterans for support and disclose their desire to take their own life without fear of judgment. Here, informants were having each other's backs and everyone was taking responsibility for others' lives. Thus, these spaces imbued features that enable the performance of camaraderie in civilian contexts. As part of the transition process, these veterans who are building infrastructure are engaging in routine practices through which they are building infrastructures of support, while also maintaining them and aiding others who are transitioning into civil society.

Through our analysis, the services being developed by veterans, on a basic level, served as alternatives to formal service arrangements. Whereas the VA had failed to address many needs of veterans, the veteran community is engaging in bottom-up endeavors and developing online and hybrid community spaces as a means of empowering veterans in lieu of the lack of services available to them.

3.2.2 Infrastructuring as Routinely Rebuilding the Self. Whereas we previously described how these bottom-up infrastructures served counter to formal institutional infrastructures and services, such as those available through the VA, on a deeper level, we found that the routine performance of infrastructuring was also a reflexive practice through which people were also routinely rebuilding their own lives. We next explicate the reflexive capacity of infrastructuring.

Importantly, whereas we previously described how collectivism and camaraderie are normative logics that are performed in the military, leadership is also a value that is normative and practiced by military service members [82]. Military leaders are often responsible for overseeing teams ranging from 5 to 30 people, ensuring the success of their mission by giving orders, and sometimes, controlling every aspect of the lives of those who were under their command [82]. A prevailing discovery in our data was that our veteran informants who were routinely engaging in infrastructuring had lost this sense of responsibility for others as civilians. As former military leaders, this absence was particularly acute: 
“...good leadership is not about you, it's about empowering those that work with you. All of those aspects of the army really resonated with me, and I carried that with me into my life as a civilian."

We found that in conceiving and routinely implementing and maintaining these transitional infrastructures, these veterans were invoking routine leadership performances from the military, which were missing for them, personally, in civilian contexts. Re-enacting these routine performances through the routine performance of infrastructuring enabled them to re-engage routines for making decisions on behalf of subordinates, which helped them regain a sense of purpose while in transition:

"However, when my brother who enlisted exited the military, he was truly, truly suffering. I started helping him, mentoring him, and realized that this kind of responsibility was missing in my life. This helped me recognize that he and I were not the only ones going through this... I decided to build my online space, bring in my friends, friends of friends, and other people, because the reflection that there is a real need here for an organization that addresses these social needs... It was a way to reclaim myself. . . and my sense of purpose through leadership."

As illustrated by the above example, our informants were leveraging the performance of leadership in a new way, which, in turn, helped them to see that they could extend these performances outside of military contexts by creating opportunities through which they could exercise responsibility for their peers. Through routine infrastructuring performances, veterans were reflexively reprising the roles that had given them meaning and purpose.

\subsection{Infrastructuring in the LGBTQ "Coming Out" Experience}

This case is based on a qualitative interview study (conducted between May 2018 and August 2018) with 31 LGBTQ identifying people as they engage in the "coming out" experience whereby they are articulating their inner identity to themselves and the outside world. The focus of this study was centered on understanding the emergent issues LGBTQ people experience while undergoing the "coming out" experience. The interviews were semi-structured life histories, where we explored informants' uses of technological resources in the context of their lives and lived experiences. Specifically, we focused on the ways in which they routinely adopt and re-appropriate digital infrastructures-in this case, transformative fandom such as Archive of Our Own (AO3)-to engage in identity work performances, where identity work is the process through which people make sense of their identities [15]. Transformative fandom is a unique context through which to explore identity work, as fandom communities are places through which people remix existing media properties, such as movies, television shows, and video games, through fanworks. Here, fanworks are narratives that are written by fans-in this case, people who participate in fandom communities-whereby they take existing worlds and create their own stories [19-21].

Our informants were diverse in age (18-47), and gendered identity, where they identified as nonbinary (6 participants), cisgender women (16 participants), agender (3 participants), genderqueer (3 participants), and transgender men (3 participants). Moreover, while the majority identified as White American, they were also diverse with respect to racial and ethnic identity, including Filipino (resides in the Philippines), mixed race (Asian-American), Polish (resides in the United Kingdom), Spanish (resides in Spain), Russian-American, and Ashkenazi Jew (resides in the United States). Lastly, the majority of informants lived across the continental United States (in various States such as Georgia, California, and New York), as well as other countries such as the Philippines, Spain, and the UK. 
Importantly, interviews revealed that the "coming out" experience is a lifelong endeavor-that is, it starts at birth, and can last a lifetime. This experience is complicated by the fact that LGBTQ people live in a world where people are often unaccepting of their identities, and where their identities are relegated to the margins-that is, they are on the outside of what is considered "normal." As described by our informants, many LGBTQ people live in home environments where their friends and family are unaccepting of queer identities. Moreover, the routines and normative logics that permeate the infrastructures they inhabit everyday served to routinely discriminate against their identities, such as in educational environments where teachers and peers were also unaccepting, and through mass media infrastructures that often perpetuate ill-conceived and often problematic conceptualizations of queer identity $[22,34]$. As such, LGBTQ people can be disconnected from examples of how to enact a queer identity, and are often immersed in hostile environments that are prejudiced against them [22,34], which, in turn, complicate their ability to engage in routine identity work as manifest in the "coming out" experience.

Whereas informants described being embedded in queerphobic and hostile environments across country and cultural contexts, all of our participants started using technological resources, such as Tumblr and AO3 most regularly, and participants were using these sites to write and share fan fiction, as well as talk with other community members. Here, we will describe how vis-a-vis emerging routine infrastructuring practices through $\mathrm{AO} 3$, participants were building infrastructures to counter and push back against everyday systemic marginalization.

\subsubsection{Infrastructuring as Building Counter Narratives: Pushing Back Against Systemic Marginal-} ization. Through our analysis of informant accounts, we find that LGBTQ people are developing infrastructures through which they can routinely and safely engage in identity work. Specifically, our informants were using transformative fandom communities for this purpose. While the majority initially started using fandom communities such as fanfiction.net and Live Journal, over time they all adopted and started using $\mathrm{AO} 3$. AO3, unlike other communities, was designed specifically with inclusivity and accessibility in mind [20]. Moreover, AO3 is an open-source and volunteer run platform that was created by and for fans.

Through our analysis, we find that through routine infrastructuring practices, informants reappropriated $\mathrm{AO} 3$ to serve as an identity work infrastructure. As such, people were building resilience through the ability to revise their own identities, by developing community resources through which other people could revise their own identities, and by reconstructing the routines and normative logics that have come to dominate the spaces they inhabit, such as those depicted by mass media channels, which will be elaborated below.

Our informants described how, in living in spaces where they could not disclose their identities to family members and peers, they did not possess the ability to reflexively engage in routine identity work performances. In some cases, participants were living in more conservative leaning cultural environments, such as our participants who were of Asian American and Pacific Islander descent, or in more conservative leaning geographic locations, such as rural Georgia, making identity work a burden. As described by an informant who identified as mixed race Asian American:

"My dad's side of the family is of Chinese descent. . . and culturally, it is taboo to discuss being gay, and so I had to hide that part of myself."

However, even when participants lived in home environments that were more accepting of LGBTQ identities, they were still subjected to everyday marginalization through the other spaces they inhabited, such as school and the media environment. This is best exemplified by the following quote: 
"I was initially reluctant to give myself any kind of identity in terms of being part of the queer community because I was trying work through a lot of internalized homophobia because of the conservative leanings of a lot of my classmates and just the people I was interacting with."

Through their routine engagement in, and repurposing of, fandom communities and especially $\mathrm{AO} 3$, however, informants started producing fanfiction, whereby they were able to playfully recraft their identities through narrative construction. That is, our informants described the process of writing as a reflexive practice whereby they could, through remixing existing media properties, better understand their own internalized identities:

"Through my experiences [in fandom], I was able to explore being a lesbian without being judged by my family and friends. . I felt safe. . . I could write about two lesbian characters who were in love, and who were having sex, which was something I couldn't really experience elsewhere..."

Moreover, in writing about their own internalized identities, the fanfiction works produced by our informants became a community resource. That is, the narratives they were producing served as a resource that other LGBTQ people could look to for their own identity work-that is, it normalized an otherwise marginalized identity for other members of the community:

"When I first started exploring Fandom, it soon became the most profound experience of my life. I was reading all of these fanfiction works produced by people who were like me... like, people were writing about two men being together, and that it was in fact normal and something I shouldn't be ashamed of. . . that helped me accept my own identity, and I am eternally grateful... "

On a deeper level, the routine infrastructuring through the generation of community narratives served to collectively counter the routines and logics that have become internalized in the infrastructures that permeate our society, such as media infrastructures:

"I think one of the most important parts of fandom, and the works that we are creating, is that we are really pushing back against dominant depictions of queerness. . like, why is it that in every [television] show or movie, the queer character is always the one that is unhappy?"

To better explore this phenomenon, we draw on Snow [69], who describes how collective action often challenges dominant routines and logics through acts of resistance. In this view, the performance of routine infrastructuring, through the generation of community narratives, was transformative, serving as an opportunity through which people were, at once, building resilience by reflexively engaging in identity work, normalizing LGBTQ identity for others, and also, resisting and countering the systemic marginalization of LGBTQ identity.

\section{DISCUSSION}

Through a case study exploration, we presented on three different types of prolonged disruption, and illustrate how technology serves as a resource through which people build everyday resilience. More specifically, we described how people developed sensible innovations through routine infrastructuring practice, whereby they were, in turn, building resilience. We next build on our findings in three critical and important ways. We first explicate the properties of infrastructure that promote resilience. We then describe how infrastructuring is generative of resilience. Finally, we briefly conclude with how infrastructuring is a form of care work that is oriented towards individuals, communities, and society, more broadly. 


\subsection{What is Infrastructure (that Promotes Resilience)?}

We begin with Star and Ruhleder, who ask an important question-What is infrastructure? Here, we build on this question to more deeply interrogate what it is about infrastructures that enable resilience by asking: What is Infrastructure (that Promotes Resilience)? More specifically, through a deeper analysis of our findings, we find that the perpetual creation, maintenance, and activities of the social infrastructure-or in this case, the human infrastructure-supports the evocation of resilience.

Similarly, Klinenberg [33] describes the role that local community and civic organizations played during the Hurricane Sandy response, such as checking up on one another and sharing information about food and resources. Similar ideas have been proposed by Jane Jacobs in her ethnographic accounts of how active public spaces in cities support an implicit trust among neighbors [32], and Robert Putnam in his analysis of how civic organizations help facilitate citizen engagement [55] In this view, the social infrastructure acts as a social glue that transforms and adapts in an effort to address the experiences of those living through disruption. Across all of our case studies, for example, we found that it was the efforts of people that led to the evocation of resilience.

In returning to the routine dynamics perspective, routines comprise two interacting parts-the ostensive and the performative-where the ostensive refers to the abstract label (i.e. traveling to work) and the performative refers to how people perform that routine [53]. In our study, we found that people could not readily engage in the performative aspects of their routines as a result of issues related to the infrastructure, more broadly. Citizens living in Iraq during the Second Gulf War were exposed to common threats, such as bombings, which made it difficult to travel. Veterans, who were trying to navigate civilian society, were unable to leverage existing infrastructures to manage mental health issues or adapt to civilian social settings. LGBTQ people were being constantly marginalized through the heteronormative logics built into existing systems, such as mass media environments. In turn, we found that through the adoption, use, and re-appropriation of technology, members of the social infrastructure developed new ostensive infrastructuring practices, which in turn, enabled themselves and others to build resilience. For example, as a means of performing routine educational practices, medical students in Iraq developed new ostensive routines as educational curators. Through the performance of these new ostensive routines, students were, in turn, enabling themselves and others to engage in the former ostensive routine-educational performance-through they were generating new ways in which this practice could be performed, such as through the use of Social Media to obtain information and view grades.

\subsection{When is Infrastructure (Generating Resilience)?}

We next return to Star and Ruhleder who also ask: When is Infrastructure? Here, we build on this question to more deeply interrogate the properties of infrastructuring practice that enable resilience, by asking: When is Infrastructure (generating resilience)? To frame this exploration, we draw on the concept of generativity $[10,40]$. In this view, when people use, re-purpose, or build infrastructure, they are generating new ways of experiencing their social worlds. In using this frame, through a deeper analysis of our findings, we find that infrastructuring practice is generative of the evocation of resilience in myriad ways, which have impact on individuals, communities, and society.

4.2.1 Infrastructuring as Generating Competence. The first property of infrastructuring practice that generated resilience is that it helps build infrastructural competence. Sawyer and colleagues [58] describe how information is often fragmented across different digital platforms, and infrastructural competence is, in turn, the ability of people to bring various devices together in useful alignment to support work. In this view, then, the authors argue that infrastructural competence is an important 
form of digital literacy where, in order for people to engage in routine practices, they must be aware of how socio-technical systems work together such that they can bring them into alignment. Our work extends on this concept, whereby we argue that through infrastructuring practice, people build infrastructural competence. Infrastructuring is a means through which people develop an understanding of the visible and invisible social and technical processes and practices underlying infrastructures. That is, while infrastructures are often invisible and become visible upon breakdown, through infrastructuring practice, people were able to make sense of how infrastructures work and fail, which is a critical component in enabling human systems to develop new infrastructures that promote the maintenance of everyday life, or in pushing back against heteronormative systems. We find that there exists an 'infrastructure paradox' where, on the one hand, through infrastructuring practice, people are reproducing the practices of everyday life. On the other hand, infrastructuring practice also transforms the cultural norms and practices of the societies in which people are embedded.

4.2.2 Infrastructuring as Generating Reflexivity: Restoring Control. The second property of infrastructuring practice that generated resilience was through how, as a reflexive practice, people were restoring control over their own lives. That is, people were not relying on existing infrastructures and infrastructural arrangements; infrastructuring enables people to establish control over their own futures. For example, in our study, we found that college students in Iraq took on new roles, which, in turn, allowed them to maintain their education practices. On a deeper level, the reflexivity of infrastructuring practice also allows people to rebuild themselves, and restore control over their personal experiences. For example, we found that veterans, through infrastructuring practice, were able to reflect on what gave them meaning and purpose in life, and re-engage that part of themselves in a new context.

4.2.3 Infrastructuring as Generating Security. The third property of infrastructuring practice that generated resilience is that people were also building security. Giddens [23] defines ontological security as a stable mental state derived from the continuity and predictability of routines-that is, a person achieves a sense of trust and safety in their lives through the enactment and habitualization of routines. For example, repeatedly engaging in routine behavior, such as going to work or school every day, generates a sense of reliability in a person's life; it is this sense of reliable stability that provides one with the sense of security about their existence. When these routines are disrupted, this can lead to insecurity and anxiety. We find that infrastructuring was actually producing security, as people were generating ways in which they could habitually build resilience in disruption.

4.2.4 Infrastructuring as Generating Alternative Pathways. The fourth property of infrastructuring practice that generated resilience is that it reveals alternative pathways through which people manage disruptions. On the one hand, people were building alternative infrastructures through which they and others could more successfully adapt to their disruptions. Beyond being able to adapt and manage their disruptions, we find that infrastructuring also led to innovations that may not have been possible otherwise. For example, in Iraq, whereas people initially started to engage in routine infrastructuring to resolve issues with the electric infrastructure, through the routine engagement in this practice they soon realized that they could turn a profit, thus also building entrepreneurial identities.

4.2.5 Infrastructuring as Revising Normativity. The final property of infrastructuring practice that generated resilience was through how infrastructuring revises normativity. That is, when people engage in infrastructuring, they are routinely designing in use. We found that through infrastructuring practice, not only were people trying to build capacity to gain a foothold in their daily lives, but that infrastructuring also serves to counter what is normative. To develop this concept, we draw

Proc. ACM Hum.-Comput. Interact., Vol. 3, No. CSCW, Article 73. Publication date: November 2019. 
on Feminist Science and Technology Studies (FSTS). Specifically, this work critiques the normative assumptions embedded in socio-technical systems, such as infrastructures. For example, in her formative work, Donna Haraway [28] uses the metaphor of a cyborg to uncover and question the power of binary demarcations such as able/disabled, male/female, straight/queer, and human/machine. In this view, information systems are often designed around these normative binaries which can serve to further marginalized people's identities. In the case of LGBTQ identifying individuals, the design of existing communities, digital technologies, and services, are often implicated in institutionalized binaries, e.g. straight/queer. For example, there exist intuitional norms for identity management on social media platforms, such as Facebook, which does not consider the multiplicity of people's identities. Infrastructuring practice, in turn, serves as a kind of collective engagement through which people were revising the binary, heteronormative assumptions, about their own identity.

\section{CONCLUDING REMARKS: INFRASTRUCTURING RESILIENCE, INFRASTRUCTURING EVERYDAY CARE}

Whereas we have, in this study, started to more systematically uncover how technology helps people build resilience when experiencing prolonged disruptions to their daily lives, there is still a lot of work to be done in an effort of more deeply and broadly understanding and explicating the relationship between technology and resilience. Thus far, this paper has explored ways in which marginalized populations and those experiencing prolonged disruption benefit from routine infrastructuring. However, as $\mathrm{CSCW}$ and $\mathrm{CHI}$ scholars, we are engaged in a community who is focusing more and more on the marginalized, who are by definition already vulnerable in myriad ways. Importantly, infrastructures-in this case, socio-technical systems-can serve to further marginalize people, as they are designed by people with certain values and perspectives. It is crucial, then, that we consider the moral and ethical implications of the invisible work people do when infrastructuring, as these infrastructures become embedded in the routine lives of those who use them.

To frame this conversation, we draw on scholarship from feminist and gender studies which seeks to explicate the interrelationship between technology use and design, and its societal implications $[4,5,20]$. Specifically, scholars are beginning to draw on the concept of care work $[6,14,74]$ when thinking about the moral and ethical invisibility of technology. Care work has traditionally been used to think about the moral and ethical implications of the invisible work people do to make systems, such as families, maintain momentum in their everyday lives [14, 74]. In our study, we find that when people infrastructure resilience, they are, for the most part, infrastructuring everyday care. Initially, when people routinely engage in infrastructuring, infrastructuring is geared towards caring for the self and/or their families and/or communities. Over time, ultimately, infrastructuring was geared more towards caring for society. For example, in the context of our LGBTQ case study, people initially wrote narratives to reflexively understand themselves; they then turned towards helping others in their community; and finally, they started infrastructuring as a means of pushing back against harmful heteronormative structures.

While routine infrastructuring has great potential to be used for social good, it also has the potential to harm. That is, as people try to mitigate the impacts of the everyday disruptions they face, the infrastructuring practices and subsequent socio-technical infrastructures they develop can impact people in potentially adverse ways. For example, in our Iraq case study, we observed how although people did benefit from the use of community generators, not all the providers of said generators may have necessarily had the social good in mind. These types of situations also inherently hold the potential to create more power differentials within society, as those who can afford generators and fuel gain power and economic advantage over others who need their services. As designers of socio-technical systems, it is imperative that as we develop and study

Proc. ACM Hum.-Comput. Interact., Vol. 3, No. CSCW, Article 73. Publication date: November 2019. 
socio-technical infrastructures, we continue to deeply consider both the invisible positive aspects in addition to ethical and moral dilemmas that may arise, as a form of community care work, while simultaneously thinking about how we can build socio-technical systems that promote resilience, and thus caring for others.

\section{ACKNOWLEDGMENTS}

Firstly, I thank my informants for sharing their stories and their time. Secondly, scholarship does not happen in a vacuum. As such, I want to use this as an opportunity to thank my collaborators on these various projects without whom this publication would not be possible (in alphabetical order): Ban Al-Ani, Lauren Britton, Jed Brubaker, Bryan Dosono, Brianna Dym, Casey Fiesler, and Gloria Mark. Lastly, this work was partially supported by the National Science Foundation (NSF) under award No. 1657429. Any opinions, findings, and conclusions or recommendations expressed in this material are those of the author and do not necessarily reflect the views of the NSF.

\section{REFERENCES}

[1] Konstantin Aal, George Yerousis, Kai Schubert, Dominik Hornung, Oliver Stickel, and Volker Wulf. 2014. Come_in@ Palestine: Adapting a German computer club concept to a Palestinian refugee camp. In Proceedings of the 5th ACM International Conference on Collaboration across Boundaries: Culture, Distance \& Technology. ACM, 111-120.

[2] Veterans Health Administration. [n.d.]. Review of Alleged Mismanagement at the Health Eligibility Center. http: //www.va.gov/oig/publications/report-summary.asp?id=3586

[3] Tawfiq Ammari and Sarita Schoenebeck. 2015. Understanding and Supporting Fathers and Fatherhood on Social Media Sites. In Proceedings of the 33rd Annual ACM Conference on Human Factors in Computing Systems. ACM, 1905-1914. https://doi.org/10.1145/2702123.2702205

[4] Jeffrey Bardzell and Shaowen Bardzell. 2013. What is "Critical" about Critical Design?. In SIGCHI Conference on Human Factors in Computing Systems. ACM, 3297-3306.

[5] Shaowen Bardzell. 2010. Feminist HCI: Taking stock and outlining an agenda for design. In Proceedings of the SIGCHI Conference on Human Factors in Computing Systems. ACM, 1301-1310. https://doi.org/10.1145/1753326.1753521

[6] Shaowen Bardzell, Shad Gross, Jeffrey Wain, Austin Toombs, and Jeffrey Bardzell. 2011. The significant screwdriver: care, domestic masculinity, and interaction design. In Proceedings of the 25th BCS Conference on Human-Computer Interaction. British Computer Society, 371-377.

[7] Geoffrey Bowker. 1994. Information mythology: The world of/as information. Information acumen: The understanding and use of knowledge in modern business (1994), 231-247.

[8] Geoffrey C Bowker, Karen Baker, Florence Millerand, and David Ribes. 2009. Toward information infrastructure studies: Ways of knowing in a networked environment. In International Handbook of Internet Research. Springer, 97-117.

[9] Moira Burke and Robert Kraut. 2013. Using Facebook after losing a job: Differential benefits of strong and weak ties. In Proceedings of the 2013 Conference on Computer Supported Cooperative Work. ACM, 1419-1430. https://doi.org/10. $1145 / 2441776.2441936$

[10] Bendik Bygstad. 2010. Generative mechanisms for innovation in information infrastructures. Information and Organization 20, 3-4 (2010), 156-168.

[11] Joseph J Collins. 1998. The complex context of American military culture: A practitioner's view. Washington Quarterly 21, 4 (1998), 213-228. https://doi.org/10.1080/01636609809550359

[12] L Comfort. 2007. Shared risk: Complex systems in seismic response.

[13] Jill P Dimond, Casey Fiesler, and Amy S Bruckman. 2011. Domestic violence and information communication technologies. Interacting with Computers 23, 5 (2011), 413-421. https://doi.org/10.1016/j.intcom.2011.04.006

[14] Michaelanne Dye, David Nemer, Josiah Mangiameli, Amy Bruckman, and Neha Kumar. 2018. The human infrastructure of El Paquete, Cuba's offline internet. Interactions 26, 1 (2018), 58-62.

[15] Brianna Dym, Casey Fiesler, Jed R Brubaker, and Bryan Semaan. [n.d.]. "Coming out okay": Community narratives for LGBTQ identity recovery work.

[16] Tineke M Egyedi and Donna C Mehos. 2012. Inverse infrastructures: Disrupting networks from below. Edward Elgar Publishing. https://doi.org/10.4337/9781781952290

[17] Ingrid Erickson and Mohammad Hossein Jarrahi. 2016. Infrastructuring and the challenge of dynamic seams in mobile knowledge work. In Proceedings of the 19th ACM Conference on Computer-Supported Cooperative Work \& Social Computing. ACM, 1323-1336. https://doi.org/10.1145/2818048.2820015 
[18] Martha S Feldman. 2000. Organizational routines as a source of continuous change. Organization Science 11, 6 (2000), 611-629.

[19] Casey Fiesler. 2007. Everything I need to know I learned from fandom: How existing social norms can help shape the next generation of user-generated content. Vand. J. Ent. \& Tech. L. 10 (2007), 729.

[20] Casey Fiesler, Shannon Morrison, and Amy S Bruckman. 2016. An archive of their own: A case study of feminist $\mathrm{HCI}$ and values in design. In Proceedings of the 2016 CHI Conference on Human Factors in Computing Systems. ACM, 2574-2585. https://doi.org/10.1145/2858036.2858409

[21] Casey Fiesler, Shannon Morrison, R Benjamin Shapiro, and Amy S Bruckman. 2017. Growing their own: Legitimate peripheral participation for computational learning in an online fandom community. In Proceedings of the 2017 ACM Conference on Computer Supported Cooperative Work and Social Computing. ACM, 1375-1386.

[22] Linda Garnets, Gregory M Herek, and Barrie Levy. 1990. Violence and victimization of lesbians and gay men: Mental health consequences. Fournal of Interpersonal Violence 5, 3 (1990), 366-383.

[23] Anthony Giddens. 1991. Modernity and self-identity: Self and society in the late modern age. Stanford University Press.

[24] Chris Hagar and Caroline Haythornthwaite. 2005. Crisis, farming \& community. The fournal of Community Informatics 1,3 (2005).

[25] Oliver L Haimson, Jed R Brubaker, Lynn Dombrowski, and Gillian R Hayes. 2015. Disclosure, stress, and support during gender transition on Facebook. In Proceedings of the 18th ACM Conference on Computer Supported Cooperative Work \& Social Computing. ACM, 1176-1190. https://doi.org/10.1145/2675133.2675152

[26] Foad Hamidi, Morgan Klaus Scheuerman, and Stacy M Branham. 2018. Gender recognition or gender reductionism?: The social implications of embedded gender recognition systems. In Proceedings of the 2018 CHI Conference on Human Factors in Computing Systems. ACM, 8.

[27] Ole Hanseth and Kalle Lyytinen. 2010. Design theory for dynamic complexity in information infrastructures: the case of building internet. Journal of Information Technology 25, 1 (2010), 1-19.

[28] Donna Haraway. 2006. A cyborg manifesto: Science, technology, and socialist-feminism in the late 20th century. In The International Handbook of Virtual Learning Environments. Springer, 117-158. https://doi.org/10.1007/978-1-40203803-7_4

[29] Erik Hollnagel, David D Woods, and Nancy Leveson. 2006. Resilience engineering: Concepts and precepts. Ashgate Publishing, Ltd.

[30] Herminia Ibarra and Jennifer L Petriglieri. 2010. Identity work and play. fournal of Organizational Change Management 23, 1 (2010), 10-25.

[31] Steven J Jackson. 2014. Rethinking Repair. Media technologies: Essays on communication, materiality, and society (2014), 221-239. https://doi.org/10.7551/mitpress/9780262525374.003.0011

[32] Jane Jacobs. 1992. The death and life of great American cities. 1961. New York: Vintage (1992).

[33] Eric Klinenberg. 2015. Heat wave: A social autopsy of disaster in Chicago. University of Chicago Press. https: //doi.org/10.7208/chicago/9780226026718.001.0001

[34] Julie Konik and Abigail Stewart. 2004. Sexual identity development in the context of compulsory heterosexuality. fournal of Personality 72, 4 (2004), 815-844.

[35] Matthias Korn and Amy Voida. 2015. Creating friction: Infrastructuring civic engagement in everyday life. In Proceedings of The Fifth Decennial Aarhus Conference on Critical Alternatives. Aarhus University Press, 145-156. https://doi.org/10.7146/aahcc.v1i1.21198

[36] Brian M. Landry, Eun Kyoung Choe, Stephen McCutcheon, and Julie A. Kientz. 2010. Post-traumatic stress disorder. Proceedings of the ACM International Conference on Health Informatics (2010), 780. https://doi.org/10.1145/1882992. 1883110

[37] Christopher A Le Dantec and W Keith Edwards. 2008. Designs on dignity: Perceptions of technology among the homeless. In Proceedings of the SIGCHI Conference on Human Factors in Computing Systems. ACM, 627-636. https: //doi.org/10.1145/1357054.1357155

[38] Charlotte P Lee, Paul Dourish, and Gloria Mark. 2006. The human infrastructure of cyberinfrastructure. In Proceedings of the 200620 th Anniversary Conference on Computer Supported Cooperative Work. ACM, 483-492. https://doi.org/10. 1145/1180875.1180950

[39] Caitlin Lustig and Bonnie Nardi. 2015. Algorithmic authority: The case of Bitcoin. In 2015 48th Hawaii International Conference on System Sciences. IEEE, 743-752.

[40] Kalle Lyytinen, Carsten Sørensen, and David Tilson. 2017. Generativity in digital infrastructures: A research note. In The Routledge Companion to Management Information Systems. Routledge, 253-275.

[41] S F J Mak, R Williams, and J Mackness. 2010. Blogs and forums as communication and learning tools in a MOOC. Proceedings of the 7th International Conference on Networked Learning 2010 (2010), 275-285. https://doi.org/10.1162/ dmal.9780262524834.071 
[42] Diane Maloney-Krichmar and Jenny Preece. 2005. A multilevel analysis of sociability, usability, and community dynamics in an online health community. ACM Transactions on Computer-Human Interaction 12, 2 (2005), 201-232.

[43] Siambabala Bernard Manyena. 2006. The concept of resilience revisited. Disasters 30, 4 (2006), 434-450.

[44] Gloria Mark and Bryan Semaan. 2008. Resilience in collaboration: Technology as a resource for new patterns of action. In Proceedings of the 2008 ACM Conference on Computer supported Cooperative Work. ACM, 137-146.

[45] Gloria J Mark, Ban Al-Ani, and Bryan Semaan. 2009. Resilience through technology adoption: Merging the old and the new in Iraq. In Proceedings of the SIGCHI Conference on Human Factors in Computing Systems. ACM, 689-698.

[46] Michael Massimi, Jackie L Bender, Holly O Witteman, and Osman H Ahmed. 2014. Life transitions and online health communities: reflecting on adoption, use, and disengagement. In Proceedings of the 17th ACM Conference on Computer Supported Cooperative Work \& Social Computing. ACM, 1491-1501.

[47] Michael Massimi, Jill P Dimond, and Christopher A Le Dantec. 2012. Finding a new normal: the role of technology in life disruptions. In Proceedings of the ACM 2012 Conference on Computer Supported Cooperative Work. ACM, 719-728. https://doi.org/10.1145/2145204.2145314

[48] Tsubasa Morioka, Nicole B Ellison, and Michael Brown. 2016. Identity Work on Social Network Sites: Disadvantaged Students' College Transition Processes. In Proceedings of the 19th ACM Conference on Computer-Supported Cooperative Work \& Social Computing. 848-859.

[49] National Alliance to End Homelessness. 2015. Veterans. http://www.endhomelessness.org/pages/veterans

[50] Wanda J Orlikowski. 1992. The duality of technology: Rethinking the concept of technology in organizations. Organization science 3, 3 (1992), 398-427.

[51] Leysia Palen and Sophia B Liu. 2007. Citizen communications in crisis: Anticipating a future of ICT-supported public participation. In Proceedings of the SIGCHI Conference on Human Factors in Computing Systems. ACM, 727-736.

[52] Leysia Palen and Sarah Vieweg. 2008. The emergence of online widescale interaction in unexpected events: Assistance, alliance \& retreat. In Proceedings of the 2008 ACM Conference on Computer Supported Cooperative Work. ACM, 117-126.

[53] Brian T Pentland, Martha S Feldman, Markus C Becker, and Peng Liu. 2012. Dynamics of organizational routines: A generative model. Journal of Management Studies 49, 8 (2012), 1484-1508.

[54] Volkmar Pipek and Volker Wulf. 2009. Infrastructuring: Toward an integrated perspective on the design and use of information technology. fournal of the Association for Information Systems 10, 5 (2009), 447.

[55] Robert D Putnam. 2000. Bowling alone: America's declining social capital. In Culture and Politics. Springer, 223-234.

[56] Yan Qu, Philip Fei Wu, and Xiaoqing Wang. 2009. Online community response to major disaster: A study of Tianya forum in the 2008 Sichuan earthquake. In 42nd Hawaii International Conference on System Sciences. IEEE, 1-11.

[57] Linda Resnik, Daniel W Bradford, Shirley M Glynn, Alan M Jette, C Johnson Hernandez, and Sharon Wills. 2012. Issues in defining and measuring veteran community reintegration: Proceedings of the working group on community reintegration, VA rehabilitation outcomes conference, Miami, Florida. Journal of Rehabilitation Research and Development 49 , 1 (2012), 87-100. https://search.proquest.com/docview/1011945915?accountid=14214

[58] Steve Sawyer, Ingrid Erickson, and Mohammad Hossein Jarrahi. 2019. Infrastructural competence. digitalSTS: A Field Guide for Science \& Technology Studies (2019), 267.

[59] Steven L Sayers. 2011. Family reintegration difficulties and couples therapy for military veterans and their spouses. Cognitive and Behavioral Practice 18, 1 (2011), 108-119. https://doi.org/10.1016/j.cbpra.2010.03.002

[60] Roger C Schank and Robert P Abelson. 2013. Scripts, plans, goals, and understanding: An inquiry into human knowledge structures. Psychology Press. https://doi.org/10.1016/B978-1-4832-1446-7.50019-4

[61] Barry R Schlenker, Thomas W Britt, John Pennington, Rodolfo Murphy, and Kevin Doherty. 1994. The triangle model of responsibility. Psychological Review 101, 4 (1994), 632.

[62] Nancy K. Schlossberg. 2005. Counseling Adults in Transition: Linking Practice with Theory. Springer Publishing Company.

[63] Kai Schubert, Anne Weibert, and Volker Wulf. 2011. Locating computer clubs in multicultural neighborhoods: How collaborative project work fosters integration processes. International fournal of Human-Computer Studies 69, 10 (2011), 669-678.

[64] Bryan Semaan and Gloria Mark. 2011. Technology-mediated social arrangements to resolve breakdowns in infrastructure during ongoing disruption. ACM Transactions on Computer-Human Interaction 18, 4 (2011), 21.

[65] Bryan C Semaan, Lauren M. Britton, and Bryan Dosono. 2016. Transition resilience with ICTs: 'Identity awareness' in veteran re-integration. In Proceedings of the 2016 CHI Conference on Human Factors in Computing Systems. ACM, 2882-2894. https://doi.org/10.1145/2858036.2858109

[66] Bryan C Semaan, Lauren M. Britton, and Bryan Dosono. 2017. Military masculinity and the travails of transitioning: Disclosure in social media. In Proceedings of the 20th ACM Conference on Computer Supported Cooperative Work and Social Computing. ACM. https://doi.org/10.1145/2998181.2998221

[67] Irina Shklovski, Robert Kraut, and Jonathon Cummings. 2006. Routine patterns of internet use and psychological well-being: Coping with a residential move. In Proceedings of the SIGCHI Conference on Human Factors in Computing 
Systems. ACM, 969-978. https://doi.org/10.1145/1124772.1124917

[68] Irina Shklovski, Robert Kraut, and Jonathon Cummings. 2008. Keeping in touch by technology: Maintaining friendships after a residential move. In Proceedings of the SIGCHI Conference on Human Factors in Computing Systems. ACM, 807-816. https://doi.org/10.1145/1357054.1357182

[69] David Snow. 2001. Collective identity and expressive forms. Center for the Study of Democracy (2001). https: //doi.org/10.1016/B0-08-043076-7/04094-8

[70] Paul C Sondrol. 1992. 1984 Revisited? A Re-Examination of Uruguay’s Military Dictatorship. Bulletin of Latin American Research 11, 2 (1992), 187-203.

[71] Steven M Southwick, George A Bonanno, Ann S Masten, Catherine Panter-Brick, and Rachel Yehuda. 2014. Resilience definitions, theory, and challenges: Interdisciplinary perspectives. European fournal of Psychotraumatology 5, 1 (2014), 25338.

[72] Susan Leigh Star and Karen Ruhleder. 1996. Steps toward an ecology of infrastructure: Design and access for large information spaces. Information Systems Research 7, 1 (1996), 111-134. https://doi.org/10.1287/isre.7.1.111

[73] Jeannette N Sutton, Leysia Palen, and Irina Shklovski. 2008. Backchannels on the front lines: Emergency uses of social media in the 2007 Southern California Wildfires. University of Colorado.

[74] Austin L Toombs, Shaowen Bardzell, and Jeffrey Bardzell. 2015. The proper care and feeding of hackerspaces: Care ethics and cultures of making. In Proceedings of the 33rd Annual ACM Conference on Human Factors in Computing Systems. ACM, 629-638.

[75] US Census Bureau. 2014. Facts for Feature: Veterans Day 2014: Nov. 11. http://www.census.gov/newsroom/facts-forfeatures/2014/cb14-ff24.html

[76] Susan Van Den Tillaart, Donna Kurtz, and Penny Cash. 2009. Powerlessness, marginalized identity, and silencing of health concerns: Voiced realities of women living with a mental health diagnosis. International fournal of Mental Health Nursing 18, 3 (2009), 153-163.

[77] Janet Vertesi. 2014. Seamful spaces: Heterogeneous infrastructures in interaction. Science, Technology, \& Human Values 39, 2 (2014), 264-284. https://doi.org/10.1177/0162243913516012

[78] Sarah Vieweg, Amanda L Hughes, Kate Starbird, and Leysia Palen. 2010. Microblogging during two natural hazards events: What twitter may contribute to situational awareness. In Proceedings of the SIGCHI Conference on Human Factors in Computing Systems. ACM, 1079-1088.

[79] Anne Weibert and Volker Wulf. 2010. All of a sudden we had this dialogue...: Intercultural computer clubs' contribution to sustainable integration. In Proceedings of the 3rd International Conference on Intercultural Collaboration. ACM, 93-102.

[80] Karl E Weick. 1993. The collapse of sensemaking in organizations: The Mann Gulch disaster. Administrative Science Quarterly (1993), 628-652.

[81] Karl E Weick. 1995. Sensemaking in organizations. Vol. 3. SAGE Publications.

[82] Leonard Wong, Paul Bliese, and Dennis McGurk. 2003. Military leadership: A context specific review. The Leadership Quarterly 14, 6 (2003), 657-692.

[83] George Yerousis, Konstantin Aal, Thomas von Rekowski, David W Randall, Markus Rohde, and Volker Wulf. 2015. Computer-enabled project spaces: Connecting with Palestinian refugees across camp boundaries. In Proceedings of the 33rd Annual ACM Conference on Human Factors in Computing Systems. ACM, 3749-3758.

Received April 2019; revised June 2019; accepted August 2019 